\title{
Sequential Fermentation with Selected Immobilized Non-Saccharomyces Yeast for Reduction of Ethanol Content in Wine
}

\author{
Laura Canonico, Francesca Comitini, Lucia Oro and Maurizio Ciani * \\ Dipartimento Scienze della Vita e dell'Ambiente, Università Politecnica delle Marche, Ancona, Italy
}

\section{OPEN ACCESS}

Edited by:

Giuseppe Spano,

University of Foggia, Italy

Reviewed by:

Vittorio Capozzi,

University of Foggia, Italy

Cátia Pinto,

Biocant/University of Reims Champagne Ardenne, Portugal

*Correspondence:

Maurizio Ciani

m.ciani@univpm.it

Specialty section:

This article was submitted to

Food Microbiology,

a section of the journal

Frontiers in Microbiology

Received: 11 January 2016 Accepted: 22 February 2016

Published: 11 March 2016

Citation:

Canonico L, Comitini F, Oro L and

Ciani M (2016) Sequential

Fermentation with Selected

Immobilized Non-Saccharomyces

Yeast for Reduction of Ethanol

Content in Wine.

Front. Microbiol. 7:278

doi: 10.3389/fmicb.2016.00278
The average ethanol content of wine has increased over the last two decades. This increase was due to consumer preference, and also to climate change that resulted in increased grape maturity at harvest. In the present study, to reduce ethanol content in wine, a microbiological approach was investigated, using immobilized selected strains of non-Saccharomyces yeasts namely Starmerella bombicola, Metschnikowia pulcherrima, Hanseniaspora osmophila, and Hanseniaspora uvarum to start fermentation, followed by inoculation of free Saccharomyces cerevisiae cells. The immobilization procedures, determining high reaction rates, led a feasible sequential inoculation management avoiding possible contamination under actual winemaking. Under these conditions, the immobilized cells metabolized almost $50 \%$ of the sugar in 3 days, while S. cerevisiae inoculation completed all of fermentation. The S. bombicola and M. pulcherrima initial fermentations showed the best reductions in the final ethanol content (1.6 and 1.4\% $\mathrm{v} / \mathrm{v}$, respectively). Resulting wines did not have any negative fermentation products with the exception of $H$. uvarum sequential fermentation that showed significant amount of ethyl acetate. On the other hand, there were increases in desirable compounds such as glycerol and succinic acid for S. bombicola, geraniol for $M$. pulcherrima and isoamyl acetate and isoamyl alcohol for $H$. osmophila sequential fermentations. The overall results indicated that a promising ethanol reduction could be obtained using sequential fermentation of immobilized selected non-Saccharomyces strains. In this way, a suitable timing of second inoculation and an enhancement of analytical profile of wine were obtained.

Keywords: ethanol reduction, immobilized cells, non-Saccharomyces yeast, sequential fermentation, wine

\section{INTRODUCTION}

Over the last few decades, there has been a progressive increase in the ethanol content in wine due to new wine styles arising from consumer preference, and to the global climate change that is often associated with increased grape maturity (Jones et al., 2005; Grant, 2010; MacAvoy, 2010; Alstona et al., 2011; Gonzalez et al., 2013). However, wine with high levels of ethanol can be perceived negatively due to health concerns, wine quality reduction and taxation rates according to ethanol content (Guth and Sies, 2001; Athès et al., 2004; Gawel et al., 2007). 
In this context, several lines of research are aimed at reducing the ethanol content of wines, which have generally focused on vineyard management and winemaking practices, and particularly on the de-alcoholization of wine (Belisario-Sánchez et al., 2009; Kutyna et al., 2010; Stoll et al., 2010; Schmidtke et al., 2012; Bindon et al., 2013). Considering microbiological applications, several strategies that use genetically modified Saccharomyces cerevisiae strain have also been proposed for reduction of alcohol content in wine (Ehsani et al., 2009; Kutyna et al., 2010; Varela et al., 2012). More recently, Tilloy et al. (2014) used evolution-based strategies together with breeding strategies to show that evolved or hybrid strains can led to ethanol reductions of 0.6 to $1.3 \%(\mathrm{v} / \mathrm{v})$ in comparison with the ancestral strains.

Another approach to reduce the production of ethanol might be the use of non-Saccharomyces wine yeast as part of the natural microbiota present on grapes and winemaking equipment during grape juice fermentation (Renouf et al., 2005, 2007). The use of non-Saccharomyces yeast in combination with $S$. cerevisiae has been proposed to improve the quality and enhance the complexity of wine (Jolly et al., 2014; Capozzi et al., 2015). Thus, the use of controlled multistarter fermentation using selected cultures of non-Sacharomyces and S. cerevisiae yeast strains has been encouraged (Ciani and Comitini, 2011; Comitini et al., 2011; Domizio et al., 2011; Magyar and Tóth, 2011; Di Maio et al., 2012; Ehsani et al., 2012; Morata et al., 2012; Jolly et al., 2014). In this context, non-Saccharomyces wine yeast and multistarter fermentation might have a role in the reduction of the ethanol content in wine. The wide variability amongst non-Saccharomyces yeast regarding ethanol yield, fermentation efficiency, biomass production, by-product formation, and respiro-fermentative metabolism might be used to reduce the ethanol concentration in wine. Among non-Saccharomyces wine yeasts some strains/species showed low ethanol yield and sugar consumption by respiration (Crabtree negative). Using these selected strains, $1-2 \% \mathrm{v} / \mathrm{v}$ of ethanol reduction was achieved but prolonged time of sequential inoculation or high level of acetic acid were shown (Contreras et al., 2014; Gobbi et al., 2014; Quirós et al., 2014).

Sequential fermentation adequately setup might be an attractive tool for the use of non-Saccharomyces yeast for the reduction of the ethanol content in wine. This fermentative approach, in which an initial inoculation of a non-Saccharomyces strain is followed by inoculation of the $S$. cerevisiae starter strain, would allow the metabolism of the first inoculated yeast to be exploited without too great an influence on the $S$. cerevisiae strain. To benefit from the metabolic particularities of some nonSaccharomyces yeast in sequential fermentation (i.e., low ethanol yield, low fermentation efficiency), the inoculation level and the duration of the interval between the first and second inoculations are fundamental. An enhancement of the inoculation level of non-Saccharomyces yeast will improve the competitiveness toward wild yeast and S. cerevisiae starter strain and, at the same time, this will increase the expression of their metabolic activity.

In the present study, we evaluated the initial use of immobilized non-Saccharomyces yeast in sequential fermentation trials in terms of reduction of the ethanol content in the wine. The immobilization procedures allowed high inoculation rates, with the consequent high reaction rates, to reduce the delay before the $S$. cerevisiae starter strain inoculation. This also avoids possible contamination under actual winemaking conditions, due to this late inoculation of $S$. cerevisiae.

\section{MATERIALS AND METHODS Yeast Strains}

The non-Saccharomyces yeast strains used in this study were Starmerella bombicola (formerly named Candida stellata) DiSVA66, (DBVPG \# 3827; Industrial Yeast Collection of the University of Perugia), Metschnikowia pulcherrima DiSVA269, Hanseniaspora osmophila DiSVA253, and Hanseniaspora uvarum DiSVA252. These were obtained from the Yeast Collection of the Department of Life and Environmental Sciences (DiSVA) of the Polytechnic University of Marche (Italy). All of the strains were previously selected and used in mixed fermentation trials to enhance the analytical and aromatic profile of the wine, as well as to improve the wine complexity (Ciani and Ferraro, 1998; Comitini et al., 2011; Domizio et al., 2011). These were used here as the initial fermentation trials for sequential fermentations with S. cerevisiae commercial strain Lalvin EC1118 (Lallemand Inc., Toulouse, France), which was also used in pure culture as the control.

All of the strains were maintained at $-80^{\circ} \mathrm{C}$ for long-term storage, in cryovials supplemented with $80 \%$ (w/v) glycerol as the cryoprotective agent. Subsequently, the strains were cultured on Yeast Peptone Dextrose (YPD) agar medium at $25^{\circ} \mathrm{C}$ for $48-72 \mathrm{~h}$, and stored at $4^{\circ} \mathrm{C}$.

\section{MEDIA}

\section{Synthetic Grape Juice}

Synthetic grape juice (SGJ) for the micro-fermentation trials was prepared using three different solutions: solution A $(500 \mathrm{~mL})$, solution B $(250 \mathrm{~mL})$, and solution C $(250 \mathrm{~mL})$. The three solutions were sterilized at $121^{\circ} \mathrm{C}$ for $20 \mathrm{~min}$ separately and then combined aseptically (Ciani and Ferraro, 1996). Solution A contained $110 \mathrm{~g}$ D-glucose, $110 \mathrm{~g}$ D-fructose, $10 \mathrm{mg}$ ergosterol, and $1 \mathrm{ml}$ Tween 80 . Four milliliters of ergosterol stock solution (Tween 80, 6.25 mL; ergosterol, $62.5 \mathrm{mg}$ in ethanol to make $25 \mathrm{~mL}$ ) was added to the glucose-fructose solution to complete solution A. Solution B contained $6 \mathrm{~g} \mathrm{~L}-(+)$-tartaric acid, $3 \mathrm{~g}$ $\mathrm{L}-(-)$-malic acid, and $0.5 \mathrm{~g}$ citric acid. Solution $\mathrm{C}$ was a mix of $1.7 \mathrm{~g}$ Yeast Nitrogen Base without amino acids and without ammonium sulfate (DIFCO), $0.2 \mathrm{~g} \mathrm{CaCl}_{2}, 2 \mathrm{~g}$ casamino acids, $0.8 \mathrm{~g}$ arginine- $\mathrm{HCl}, 1 \mathrm{~g} \mathrm{~L}$-(2)-proline, and $0.1 \mathrm{~g} \mathrm{~L}$-(2)-tryptophan. Solutions $\mathrm{B}$ and $\mathrm{C}$ were buffered at $\mathrm{pH} 3.5$ with $\mathrm{NH}_{4} \mathrm{OH}$ and $\mathrm{H}_{3} \mathrm{PO}_{4}$, respectively.

\section{Natural Grape Juice}

Natural grape juice (NGJ) was obtained during 2014 vintage and came from Verdicchio, a white grape variety that is grown in the Marche region, in central Italy. The main characteristics of the grape juice were: $\mathrm{pH} 3.39$; total acidity, $8.27 \mathrm{~g} / \mathrm{L}$; free $\mathrm{SO}_{2}$, 
$12 \mathrm{mg} / \mathrm{L}$; total $\mathrm{SO}_{2}, 48 \mathrm{mg} / \mathrm{L}$; malic acid, $3.3 \mathrm{~g} / \mathrm{L}$; initial sugar content, $202 \mathrm{~g} / \mathrm{L}$; yeast assimilable nitrogen, $160 \mathrm{mg} \mathrm{N} / \mathrm{L}$.

\section{Immobilization Procedures}

Modified YPD medium ( $0.5 \%$ yeast extract, $0.1 \%$ peptone, $2 \%$ dextrose, all w/v) was used to produce biomass at $25^{\circ} \mathrm{C}$ for $72 \mathrm{~h}$ in a rotary shaker $(150 \mathrm{rpm})$. This biomass, for the immobilization system, were harvested by centrifugation, washed three times with sterile distilled water and added to $2.5 \% \mathrm{Na}$-alginate (Carlo Erba, Milan, Italy), at a ratio of $5 \%$ (wet w/v). Using a peristaltic pump, this mixture was then dripped into $\mathrm{CaCl}_{2}(0.1 \mathrm{M})$ to induce gelation. After $1 \mathrm{~h}$, the beads formed were washed several times with sterile distilled water and then used immediately. The inoculum for the immobilized cells of the non-Saccharomyces was $10 \%$ (wet w/v), which corresponded to an inoculum of $c a$. $2 \times 10^{8}$ cells $/ \mathrm{mL}$ in SGJ or NGJ.

\section{Fermentation Conditions}

To evaluate the influence of the sequential inoculations using immobilized non-Saccharomyces cells on the ethanol content, several fermentation trials were set up with SGJ and NGJ. In SGJ, the inoculated immobilized non-Saccharomyces cells were removed after 48 or $72 \mathrm{~h}$, and the free $S$. cerevisiae cells $\left(1 \times 10^{6}\right.$ cell $/ \mathrm{mL}$ ) were inoculated into the partially fermented grape juice. In NGJ, the sequential fermentation trials were conducted by inoculation of the $S$. cerevisiae starter culture after only $72 \mathrm{~h}$, with and without the removal of the immobilized cells.

Cultures of $S$. cerevisiae were pre-incubated in SGJ at $25^{\circ} \mathrm{C}$ in a rotary shaker $(150 \mathrm{rpm})$ for $48 \mathrm{~h}$, harvested by centrifugation, and washed with sterile distilled water, with the procedure standardized to provide an inoculation level of $1 \times 10^{6}$ cells $/ \mathrm{mL}$. Before the $S$. cerevisiae inoculation, $1 \mathrm{~g}$ of beads containing non-Saccharomyces yeast were collected and maintained under agitation in $50 \mathrm{~mL} 1 \% \mathrm{Na}$-citrate solution (w/v) for $1 \mathrm{~h}$, to release the cells. Cell viability was then evaluated by standard plate counting techniques, in YPD medium. Parallel control trials were carried out using free $S$. cerevisiae cells only.

The fermentation trials were carried out in 1-L glass minifermenters that contained $400 \mathrm{~mL}$ SGJ or NGJ under static conditions at $25^{\circ} \mathrm{C}$ and in duplicate. The minifermenters had two ports, one for gas flow and the other for the inoculation of beads, and a septum of a glass frit, to maintain the beads in the medium and to allow carbon dioxide to come out.

The weight loss of the minifermenters due to $\mathrm{CO}_{2}$ evolution was followed until the end of the fermentation trials (constant weight for three consecutive days). Samples of media and beads were taken after $48,72 \mathrm{~h}$, and at the end of the fermentation and underwent chemical and microbiological analysis respectively.

\section{Analytical Determinations}

Ethanol was measured by gas-liquid chromatography (GLC) analysis (AOAC, 1990). Acetaldehyde, ethyl acetate, and higher alcohols were determined by direct injection into the GLC system. Samples were injected into a column of $30 \mathrm{~m} \times$ $0.32 \mathrm{~mm}$, with $0.25 \mu \mathrm{m}$ film thickness (Zebron ZB-WAXPlus; Phenomenex, Torrance, California, USA) with an internal standard of 1-pentanol (162 mg/L). Nitrogen was used as the carrier gas. A Shimadzu gas chromatograph (Japan) equipped with a flame ionization detector was used. The oven temperature ranged from $40^{\circ} \mathrm{C}$ to $200^{\circ} \mathrm{C}$. The temperature of the injector and the detector was $220^{\circ} \mathrm{C}$. The volatile compounds were extracted using an ether-hexane (1:1) extraction technique, and evaluated by capillary GLC. For quantification, and before their extraction, the samples were spiked with a known amount of 3 -octanol, as the internal standard $(1.6 \mathrm{mg} / \mathrm{l})$. A glass capillary column was used: $0.25 \mu \mathrm{m}$ Supelcowax 10 (length, $60 \mathrm{~m}$; internal diameter, $0.32 \mathrm{~mm}$ ). One microliter was injected in split-splitless mode, with $60 \mathrm{~s}$ splitless; temperature of injection, $220^{\circ} \mathrm{C}$; temperature of detector, $250^{\circ} \mathrm{C}$; carrier gas, helium; and flow rate, $2.5 \mathrm{~mL} / \mathrm{min}$. The temperature program was: $50^{\circ} \mathrm{C}$ for $5 \mathrm{~min}$; $3^{\circ} \mathrm{C} / \mathrm{min}$ to $220^{\circ} \mathrm{C}$, and then $220^{\circ} \mathrm{C}$ for $20 \mathrm{~min}$. The compounds were identified and quantified by comparisons with external calibration curves for each compound. The glucose, fructose, glycerol, and succinic acid concentrations were determined using specific enzyme kits (Megazyme International Ireland). Volatile acidity (expressed as grams acetic acid per liter) was quantified by steam distillation, according to the official analytical methods (EC, 2000).

\section{Statistical Analysis}

Analysis of variance (ANOVA) was applied to the experimental data for the main enological characteristics of the wines. The means were analyzed using the STATISTICA 7 software. The significant differences were determined using Duncan tests, and the data were considered significant if the associated $P$-values were $<0.05$.

\section{RESULTS}

\section{Fermentation Kinetics and Main Fermentation Parameters of Synthetic Grape Juice Trials}

In the SGJ fermentation trials, the inoculated immobilized nonSaccharomyces cells were removed after 48 and $72 \mathrm{~h}$, and the partial fermented SGJ was then inoculated with free S. cerevisiae cells (Figure 1). The $48 \mathrm{~h}$ SGJ trials (Figure 1A) showed that the control $S$. cerevisiae improved the fermentation kinetics compared to the sequential fermentation trials with the initial non-Saccharomyces yeast. The sequential fermentation trials in SGJ with $M$. pulcherrima and S. bombicola showed overlapping fermentation kinetics that were quicker than for the H. uvarum and $H$. osmophila. Moreover, all of the sequential fermentation trials showed less final $\mathrm{CO}_{2}$ evolved when compared to the control S. cerevisiae.

The data for the fermentation parameters of the sequential fermentations inoculated after $48 \mathrm{~h}$ in SGJ are summarized in Table 1. All of the sequential fermentation trials showed significantly lower ethanol content when compared with the control S. cerevisiae, with residual sugar less than $3 \mathrm{~g} / \mathrm{L}$. In particular, the sequential fermentation trials carried out with $M$. pulcherrima, S. bombicola, and H. uvarum showed comparable lower final ethanol production, while with $H$. osmophila there was higher ethanol content. Data for the ethanol yield basically 


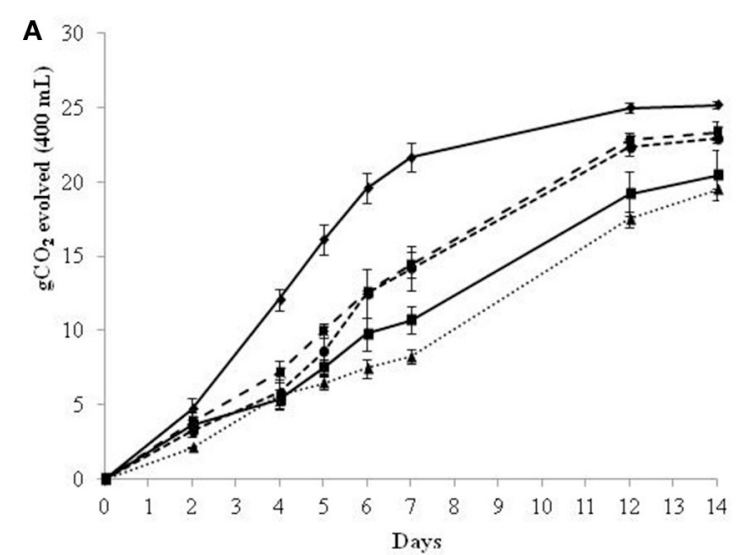

B

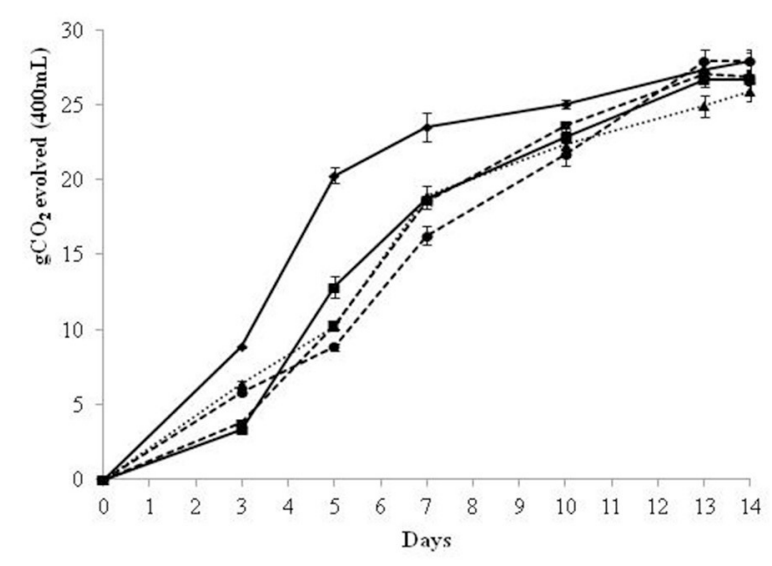

FIGURE 1 | Growth kinetics in sequential fermentation trials of immobilized non-Saccharomyces yeast and control S. cerevisiae on synthetic grape juice (SGJ). Beads were removed at $48 \mathrm{~h}$ (A) and $72 \mathrm{~h} \mathrm{(B)}$ of fermentation. $\longrightarrow$ S. cerevisiae control culture; $\cdots \cdot \cdot \cdots \cdot \cdot$. osmophila/S. cerevisiae; - - - -S. bombicola/S. cerevisiae; $\rightarrow-H$. uvarum/S. cerevisiae; - - - M. pulcherrima/S. cerevisiae.

confirmed those of ethanol production. At $48 \mathrm{~h}$ of fermentation, the control $S$. cerevisiae showed a sugar consumption of $25 \%$, while the non-Saccharomyces sequential fermentation trials using the immobilized cells, showed significantly lower sugar consumption, from 11 to $21 \%$; with the exception of $M$. pulcherrima (38\%). Again, and with the exception of $M$. pulcherrima, the other sequential fermentation trials resulted in significant increases in glycerol, in comparison with the control S. cerevisiae. For the volatile acidity, there were no significant differences seen, while the succinic acid content significant increased in all fermentation trials (with the exception of $H$. osmophila) with the immobilized non-Saccharomyces yeast, particularly with $S$. bombicola.

Since, $48 \mathrm{~h}$ sequential fermentation showed a limited sugar consumption and with the aim to enhance the fermentation performance of immobilized cells, $72 \mathrm{~h}$ sequential fermentation was evaluated. In $72 \mathrm{~h}$ SGJ sequential fermentation trials (Figure 1B), the control S. cerevisiae showed essentially the same fermentation kinetics as described above for the $48 \mathrm{~h}$ trials. Over these first 3 days of fermentation with the immobilized non-Saccharomyces species, H. osmophila, and S. bombicola showed enhanced fermentation kinetics in comparison with $M$. pulcherrima and $H$. uvarum. After removal of the beads and inoculation of $S$. cerevisiae, all of the sequential fermentation trials showed lower fermentation kinetics when compared with the control $S$. cerevisiae, although all condition achieved comparable amounts of $\mathrm{CO}_{2}$ evolution at the end of the fermentation trials.

In this regard, the inoculation delay for the addition of free S. cerevisiae cells from 48 to $72 \mathrm{~h}$ resulted in further reductions in ethanol content in comparison with the control S. cerevisiae, paired with a small increase in the residual sugars (Table 2). $H$. uvarum was the only sequential fermentation trial that did not show any difference in ethanol reduction from the 48 to $72 \mathrm{~h}$ inoculation of $S$. cerevisiae. Data for the ethanol yield confirmed this trend. Indeed, and with the exception of H. uvarum, all of these sequential fermentation trials showed a significant reduction in ethanol yield in comparison with the control $S$. cerevisiae. As expected, there was increased sugar consumption of the immobilized non-Saccharomyces yeast from 48 to $72 \mathrm{~h}$, which varied from 37 to $52 \%$ of total sugars. For glycerol content, only the S. bombicola and H. uvarum sequential fermentation trials showed a significant increase when compared with the control S. cerevisiae (Table 2). All sequential fermentation trials showed significant, but limited, increases in volatile acidity and succinic acid (although the succinic acid content did not reach statistical significance for $H$. uvarum).

\section{Fermentation Kinetics and Main Fermentation Parameters of Natural Grape Juice Trials}

After identifying the delay time of the inoculum of $S$. cerevisiae starter $(72 \mathrm{~h})$ that allows the immobilized cells to consume around $50 \%$ of initial sugars in a synthetic medium, we carried out non-Saccharomyces immobilized cells sequential fermentations in NGJ (Verdicchio grape juice) to evaluate the overall fermentation parameters and the analytical profile of wines. The fermentation kinetics of the sequential fermentation trials in NGJ, conducted with the removal of the immobilized cells, showed similar behaviors to those in SGJ for $72 \mathrm{~h}$ (Figure 2A). Different fermentation kinetics were shown in NGJ without the removal of beads, and hence in the continued presence of the immobilized non-Saccharomyces species (Figure 2B). These data highlighted that in the presence of the immobilized cells during the whole fermentation process, this resulted in increased fermentation kinetics by day 7 , with the same $\mathrm{CO}_{2}$ evolved as for the control S. cerevisiae. After this time, all of the fermentation kinetics showed overlap (Figure 2B).

The data regarding to the main fermentation parameters in NGJ both with or without beads removal are reported in Table 3, and they confirm the significantly lower ethanol content in all of the sequential fermentation trials, in comparison with the control $S$. cerevisiae, which were all accompanied by little or no residual sugars $(<2 \mathrm{~g} / \mathrm{L})$. 


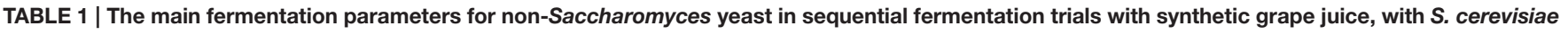
EC1118 inoculated after $48 \mathrm{~h}$ of fermentation.

\begin{tabular}{|c|c|c|c|c|c|c|c|}
\hline \multirow{2}{*}{$\begin{array}{l}\text { Fermentation } \\
\text { trials }\end{array}$} & \multirow{2}{*}{$\begin{array}{c}\text { Sugar } \\
\text { consumed at } \\
48 \mathrm{~h}(\%)\end{array}$} & \multicolumn{6}{|c|}{ End of fermentation } \\
\hline & & $\begin{array}{c}\text { Sugar } \\
\text { consumed }(g / L)\end{array}$ & Ethanol (\% v/v) & Ethanol yield $(\mathrm{g} / \mathrm{g})$ & Glycerol (g/L) & $\begin{array}{c}\text { Volatile acidity (as } \\
\text { acetic acid g/L) }\end{array}$ & Succinic acid $(g / l)$ \\
\hline $\begin{array}{l}\text { S. cerevisiae } \\
\text { control culture }\end{array}$ & $24.56 \pm 0.62^{a}$ & $218.77 \pm 0.10^{b}$ & $12.54 \pm 0.02^{a}$ & $0.452 \pm 0.001^{a}$ & $5.32 \pm 0.44^{b}$ & $0.38 \pm 0.02^{d}$ & $0.37 \pm 0.04^{c}$ \\
\hline $\begin{array}{l}\text { H. osmophila/S. } \\
\text { cerevisiae }\end{array}$ & $20.98 \pm 0.01^{b}$ & $217.83 \pm 0.05^{c}$ & $11.76 \pm 0.12^{b}$ & $0.426 \pm 0.004^{b}$ & $6.70 \pm 0.02^{a}$ & $0.54 \pm 0.01^{c}$ & $0.44 \pm 0.06^{b, c}$ \\
\hline $\begin{array}{l}\text { M. pulcherrima/S. } \\
\text { cerevisiae }\end{array}$ & $38.33 \pm 0.01^{c}$ & $219.41 \pm 0.04^{a}$ & $11.40 \pm 0.07^{c}$ & $0.410 \pm 0.002^{c}$ & $5.64 \pm 0.29^{b}$ & $0.63 \pm 0.02^{b}$ & $0.53 \pm 0.04^{b}$ \\
\hline $\begin{array}{l}\text { S. bombicola/S. } \\
\text { cerevisiae }\end{array}$ & $17.42 \pm 0.75^{d}$ & $217.67 \pm 0.14^{c}$ & $11.36 \pm 0.01^{c}$ & $0.412 \pm 0.000^{c}$ & $7.54 \pm 0.70^{a}$ & $0.57 \pm 0.00^{\mathrm{C}}$ & $1.03 \pm 0.01^{a}$ \\
\hline $\begin{array}{l}\text { H. uvarum/S. } \\
\text { cerevisiae }\end{array}$ & $10.56 \pm 1.71^{\mathrm{e}}$ & $218.83 \pm 0.05^{b}$ & $11.48 \pm 0.00^{C}$ & $0.414 \pm 0.000^{c}$ & $6.99 \pm 0.07^{a}$ & $0.68 \pm 0.01^{a}$ & $0.49 \pm 0.01^{b}$ \\
\hline
\end{tabular}

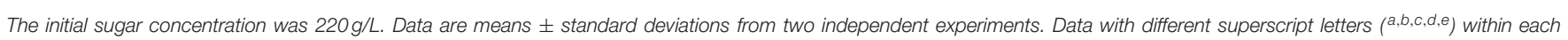
column are different according to Duncan tests (0.05\%).

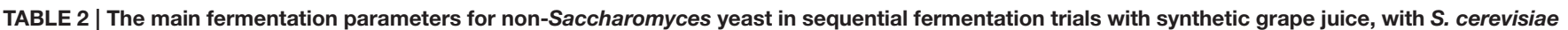
EC1118 inoculated after $72 \mathrm{~h}$ of fermentation.

\begin{tabular}{|c|c|c|c|c|c|c|c|}
\hline \multirow{2}{*}{$\begin{array}{l}\text { Fermentation } \\
\text { trials }\end{array}$} & \multirow{2}{*}{$\begin{array}{c}\text { Sugar } \\
\text { consumed at } \\
72 \mathrm{~h} \mathrm{( \% )}\end{array}$} & \multicolumn{6}{|c|}{ End of fermentation } \\
\hline & & $\begin{array}{l}\text { Sugar } \\
\text { consumed }(g / L)\end{array}$ & Ethanol (\% v/v) & Ethanol yield (g/g) & Glycerol (g/L) & $\begin{array}{c}\text { Volatile acidity (as } \\
\text { acetic acid g/L) }\end{array}$ & Succinic acid (g/L) \\
\hline $\begin{array}{l}\text { S. cerevisiae } \\
\text { control culture }\end{array}$ & $43.82 \pm 0.03^{b}$ & $220.00 \pm 0.11^{a}$ & $12.36 \pm 0.27^{a}$ & $0.443 \pm 0.009^{a}$ & $5.18 \pm 0.07^{c}$ & $0.36 \pm 0.00^{d}$ & $0.39 \pm 0.00^{c}$ \\
\hline $\begin{array}{l}\text { H. osmophila/S. } \\
\text { cerevisiae }\end{array}$ & $52.16 \pm 2.30^{a}$ & $216.90 \pm 0.28^{C}$ & $11.03 \pm 0.16^{b}$ & $0.401 \pm 0.005^{\mathrm{b}, \mathrm{c}}$ & $5.25 \pm 0.17^{c}$ & $0.66 \pm 0.01^{a}$ & $0.71 \pm 0.10^{b}$ \\
\hline $\begin{array}{l}\text { M. pulcherrima/S. } \\
\text { cerevisiae }\end{array}$ & $37.22 \pm 2.12^{d}$ & $217.79 \pm 0.04^{b}$ & $11.01 \pm 0.22^{b}$ & $0.400 \pm 0.008^{\mathrm{C}}$ & $5.07 \pm 0.02^{\mathrm{C}}$ & $0.51 \pm 0.01^{b}$ & $0.59 \pm 0.03^{b}$ \\
\hline $\begin{array}{l}\text { S. bombicola/S. } \\
\text { cerevisiae }\end{array}$ & $42.20 \pm 1.63^{b}$ & $216.74 \pm 0.14^{C}$ & $11.08 \pm 0.00^{b}$ & $0.403 \pm 0.000^{\mathrm{b}, \mathrm{c}}$ & $7.46 \pm 0.01^{a}$ & $0.49 \pm 0.01^{b, c}$ & $1.12 \pm 0.10^{\mathrm{a}}$ \\
\hline $\begin{array}{l}\text { H. uvarum/S. } \\
\text { cerevisiae }\end{array}$ & $39.54 \pm 071^{\mathrm{C}}$ & $215.86 \pm 0.37^{d}$ & $11.58 \pm 0.43^{b}$ & $0.423 \pm 0.000^{a, b}$ & $6.18 \pm 0.19^{b}$ & $0.47 \pm 0.01^{\mathrm{c}}$ & $0.55 \pm 0.01^{b, c}$ \\
\hline
\end{tabular}

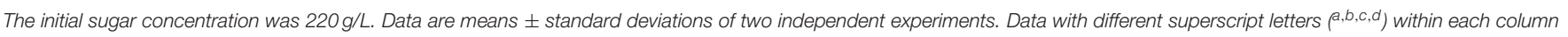
are different according to Duncan tests (0.05\%).

The same was also observed for the ethanol yield, which confirmed that the reduction of ethanol content was mainly due to the lower yield. In this context, the main by-products showed some variations: the S. bombicola sequential fermentation trial confirmed the highest production of glycerol and succinic acid as previously reported (Ciani and Ferraro, 1998), while H. osmophila showed the lowest glycerol content. Compared to the control S. cerevisiae, in the NGJ sequential trials $H$. uvarum showed a significant increase in volatile acidity, while the other sequential fermentation trials showed comparable or lower values.

\section{Viability and Cell Release from the Beads}

Two important features to monitor in the use of these immobilized cells are the loss of cell viability and the cells released from the beads, which is closely related to the conservation of the structure of the matrix. The data reported in Table 4 show that in SGJ, the viability of all of the non-Saccharomyces yeast after 48 and $72 \mathrm{~h}$ was around $1 \times 10^{9} \mathrm{cell} / \mathrm{g}$, without significant loss of cell viability after their use. The low levels of cells released after their use $\left(\mathrm{ca} .1 \times 10^{2} \mathrm{cell} / \mathrm{mL}\right.$ after $48 \mathrm{~h}$, and $1 \times 10^{3} \mathrm{cell} / \mathrm{mL}$ after $72 \mathrm{~h}$ ) confirmed the high cell viabilities, thus indicating the good integrity of the beads. In NGJ, there was comparable high cell viability, although there was also an increase in the cell release (about $1 \times 10^{4} \mathrm{cell} / \mathrm{mL}$ ), which indicated some break-up of the matrix.

\section{Ethanol Reduction}

Figure 3 summarizes the ethanol reductions obtained across all of the sequential and control fermentation trials. The data for SGJ indicate that the delay in the S. cerevisiae inoculation from 48 to $72 \mathrm{~h}$ generally promoted further ethanol reductions. Indeed, from 48 to $72 \mathrm{~h}$, the ethanol reductions were from 1.18 to $1.28 \%(\mathrm{v} / \mathrm{v})$ for $S$. bombicola, from 1.14 to $1.35 \%(\mathrm{v} / \mathrm{v})$ for M. pulcherrima, and from 0.78 to $1.33 \%(\mathrm{v} / \mathrm{v})$ for H. osmophila. In contrast, this was opposite for $H$. uvarum, that ranged from 

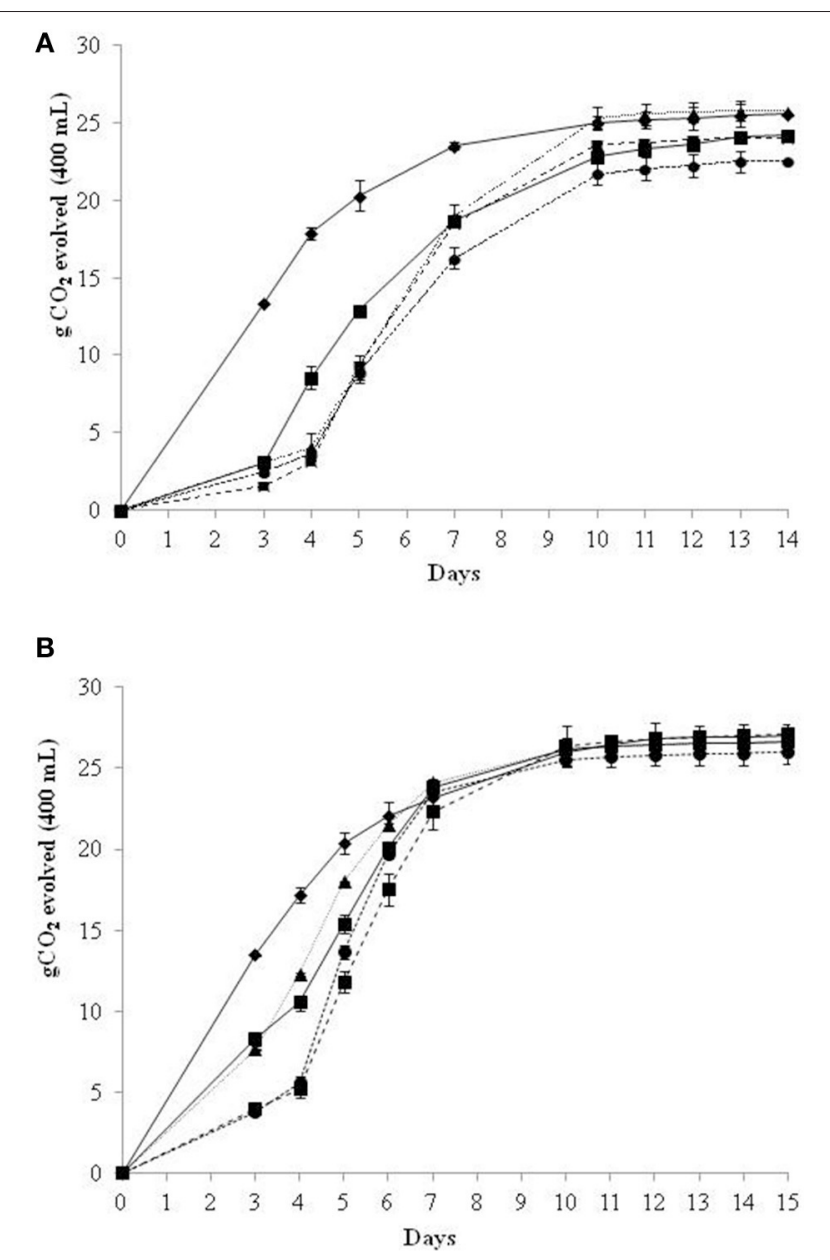

FIGURE 2 | Growth kinetics in sequential fermentation trials of immobilized non-Saccharomyces yeast and control S. cerevisiae on natural grape juice (NGJ). Beads were removed at $72 \mathrm{~h}$ (A) and without beads removal $(\mathbf{B}):-\longrightarrow$ S. cerevisiae control culture; $\cdots \cdot \cdots H$. osmophila/S. cerevisiae;--- S. bombicola/S. cerevisiae; $\rightarrow-H$. uvarum/S. cerevisiae; - - - M. pulcherrima/S. cerevisiae.

1.06 to $0.78 \%$ (v/v). In NGJ, the immobilized non-Saccharomyces yeast showed a comparable or little bit lower ethanol reduction than that exhibited by sequential fermentation trials at $72 \mathrm{~h}$ in SGJ, without any significant differences among the nonSaccharomyces species. However, significantly greater reductions in ethanol were obtained in the trials without the beads removal, thus leaving the non-Saccharomyces yeast in the fermentation trials with the S. cerevisiae. In these fermentation trials, there were generally significant improvements in the ethanol reductions over the $72 \mathrm{~h}$ NGJ sequential fermentation trials: from 1.10 to $1.46 \%(\mathrm{v} / \mathrm{v})$ for $M$. pulcherrima, from 1.17 to $1.64 \%(\mathrm{v} / \mathrm{v})$ for $S$. bombicola, and from 1.04 to $1.21 \%(\mathrm{v} / \mathrm{v})$ for H. uvarum. Only the $H$. osmophila sequential fermentation trial did not show any statistically significant variation here (from 1.04 to $1.00 \%$ [v/v]).

\section{The Main Volatile Compounds in Sequential Fermentations on Natural Grape Juice}

To determine the influence of the non-Saccharomyces sequential fermentation trials on the aromatic profile of the wine, the main volatile compounds on NGJ were assayed, and the results are summarized in Table 5.

An increase in ethyl acetate was showed in all sequential fermentations with the exception of S. bombicola trials, in both with or without beads removal. However, only $H$. uvarum sequential fermentation showed unacceptable level of this compound (around the threshold value for a negative impact on the aromatic profiles amounting to $175 \mathrm{mg} / \mathrm{L}$ ).

Regarding to the other esters, all sequential fermentations showed comparable or lower amount of phenyl ethyl acetate, ethyl hexanoate, and ethyl octanoate when compared with the control S. cerevisiae while significant increases in ethyl butyrate content was showed in S. bombicola (both with and without beads removal trials) and $H$. uvarum (only without beads removal). Furthermore, $H$. osmophila sequential fermentation showed an increase in isoamyl acetate, which is responsible of the fruity note, in both trials while M. pulcherrima and S. bombicola sequential fermentations exhibited an enhancement of this ester only without beads removal trials.

Regarding to the higher alcohols, sequential fermentations showed variable production of n-propanol. Isobutanol, amylic alcohol, and hexanol did not show significant differences between sequential fermentations and control trials while an increase in isoamyl alcohol in $H$. osmophila and $M$. pulcherrima but only without beads removal trials was found. A generalized reduction in $\beta$-phenyl ethanol content was shown in all sequential fermentation trials when compared with the control S. cerevisiae. On the contrary, an enhancement in acetaldehyde content was found in all sequential fermentations.

Regarding the volatile terpenes, a significant increase in geraniol content was exhibited by $M$. pulcherrima sequential fermentation confirming the capability of this yeast strain to liberate volatile terpens by glycosidase activity (Comitini et al., 2011).

\section{DISCUSSION}

Different microbiological approaches have been proposed to reduce the ethanol content in wine, such as genetically modified S. cerevisiae yeast (Ehsani et al., 2009; Kutyna et al., 2010; Varela et al., 2012; Rossouw et al., 2013), evolution-based strategies, together with breeding strategies (Abalos et al., 2011; Tilloy et al., 2014) and the use of non-Saccharomyces wine yeast (Contreras et al., 2014; Gobbi et al., 2014; Quirós et al., 2014).

In this last approach, the strategies include the need to manage the fermentation on the basis of several enological traits of the non-Saccharomyces species used. Several wine yeast species could be selected for their low ethanol yield, alcoholic fermentation efficiency, biomass and by-product formation as a result of the diversion of carbon away from ethanol production (Ciani and Maccarelli, 1998; Gobbi et al., 2014). On the other hand, these non-Saccharomyces wine yeasts could be used to promote sugar consumption via respiration rather than fermentation, through partial aeration of the grape juice (Gonzalez et al., 2013).

Both these approaches have indicated the promising use of non-Saccharomyces wine yeast to limit ethanol production. The use of various amounts of oxygen added during the first stages 


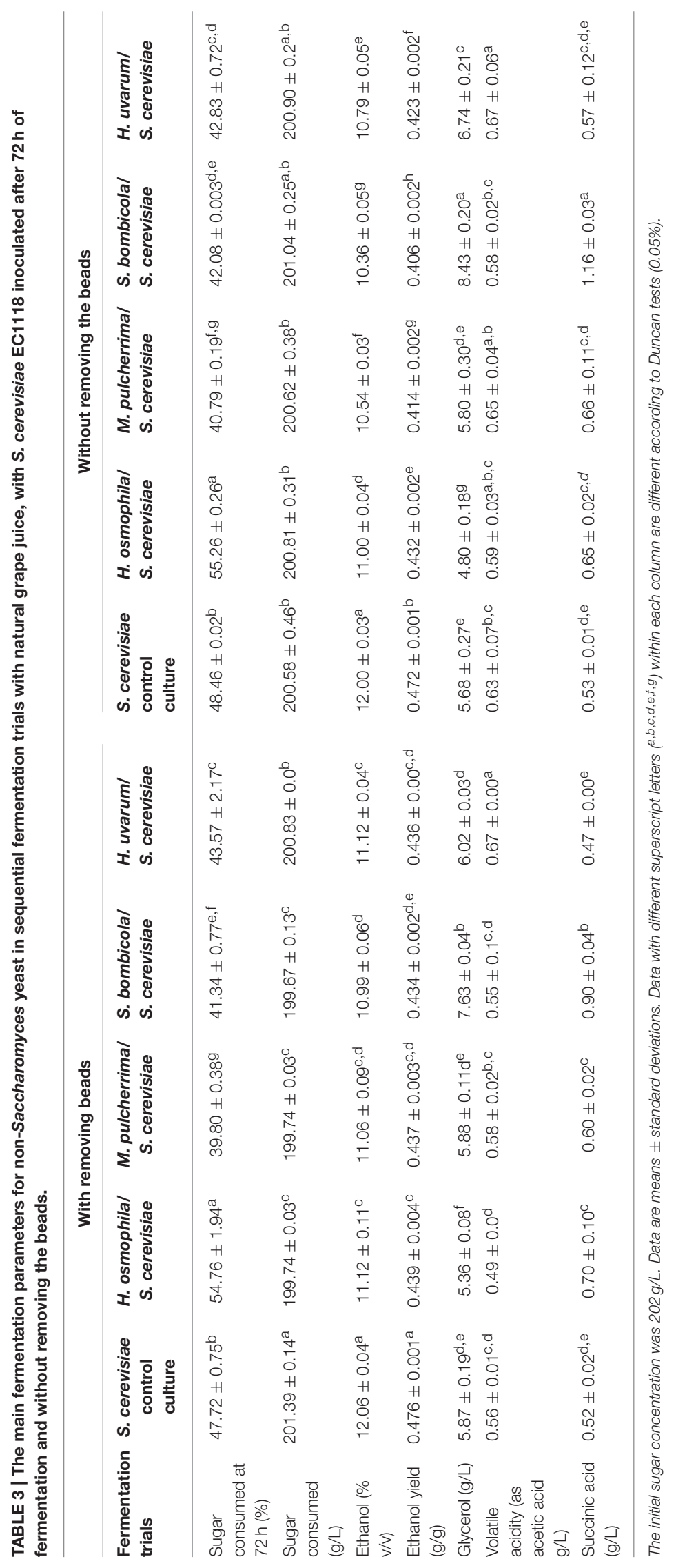


TABLE 4 | Non-Saccharomyces viable cell counts and cells released from the beads in synthetic grape juice and natural grape juice at 48 and $72 \mathrm{~h}$ of fermentation trials.

\begin{tabular}{|c|c|c|c|c|c|c|}
\hline \multirow[t]{3}{*}{ Fermentation trials } & \multicolumn{4}{|c|}{ Synthetic grape juice } & \multirow{2}{*}{\multicolumn{2}{|c|}{$\begin{array}{c}\text { Natural grape juice } \\
72 \mathrm{~h}\end{array}$}} \\
\hline & \multicolumn{2}{|c|}{$48 \mathrm{~h}$} & \multicolumn{2}{|c|}{$72 \mathrm{~h}$} & & \\
\hline & $\begin{array}{l}\text { Viable cells } \\
\text { (Log cell/g) }\end{array}$ & $\begin{array}{l}\text { Cells released } \\
\text { (Log CFU/mL) }\end{array}$ & $\begin{array}{l}\text { Viable cells } \\
\text { (Log cell/g) }\end{array}$ & $\begin{array}{l}\text { Cells released } \\
\text { (Log CFU/mL) }\end{array}$ & $\begin{array}{l}\text { Viable cells } \\
\text { (Log cell/g) }\end{array}$ & $\begin{array}{l}\text { Cells released } \\
\text { (Log CFU/mL) }\end{array}$ \\
\hline H. osmophila/S. cerevisiae & $9.64 \pm 0.01$ & $2.28 \pm 0.04$ & $9.64 \pm 0.02$ & $3.30 \pm 0.05$ & $9.36 \pm 0.21$ & $4.19 \pm 0.20$ \\
\hline M. pulcherrima/S. cerevisiae & $9.58 \pm 0.82$ & $2.03 \pm 0.01$ & $9.40 \pm 0.02$ & $3.02 \pm 0.03$ & $8.60 \pm 0.34$ & $4.64 \pm 0.11$ \\
\hline S. bombicola/S. cerevisiae & $9.40 \pm 0.70$ & $2.57 \pm 0.04$ & $9.58 \pm 0.40$ & $3.56 \pm 0.03$ & $8.60 \pm 0.34$ & $4.60 \pm 0.06$ \\
\hline H. uvarum/S. cerevisiae & $9.36 \pm 0.24$ & $2.02 \pm 0.01$ & $9.36 \pm 0.03$ & $3.25 \pm 0.10$ & $8.82 \pm 0.21$ & $4.03 \pm 0.01$ \\
\hline
\end{tabular}

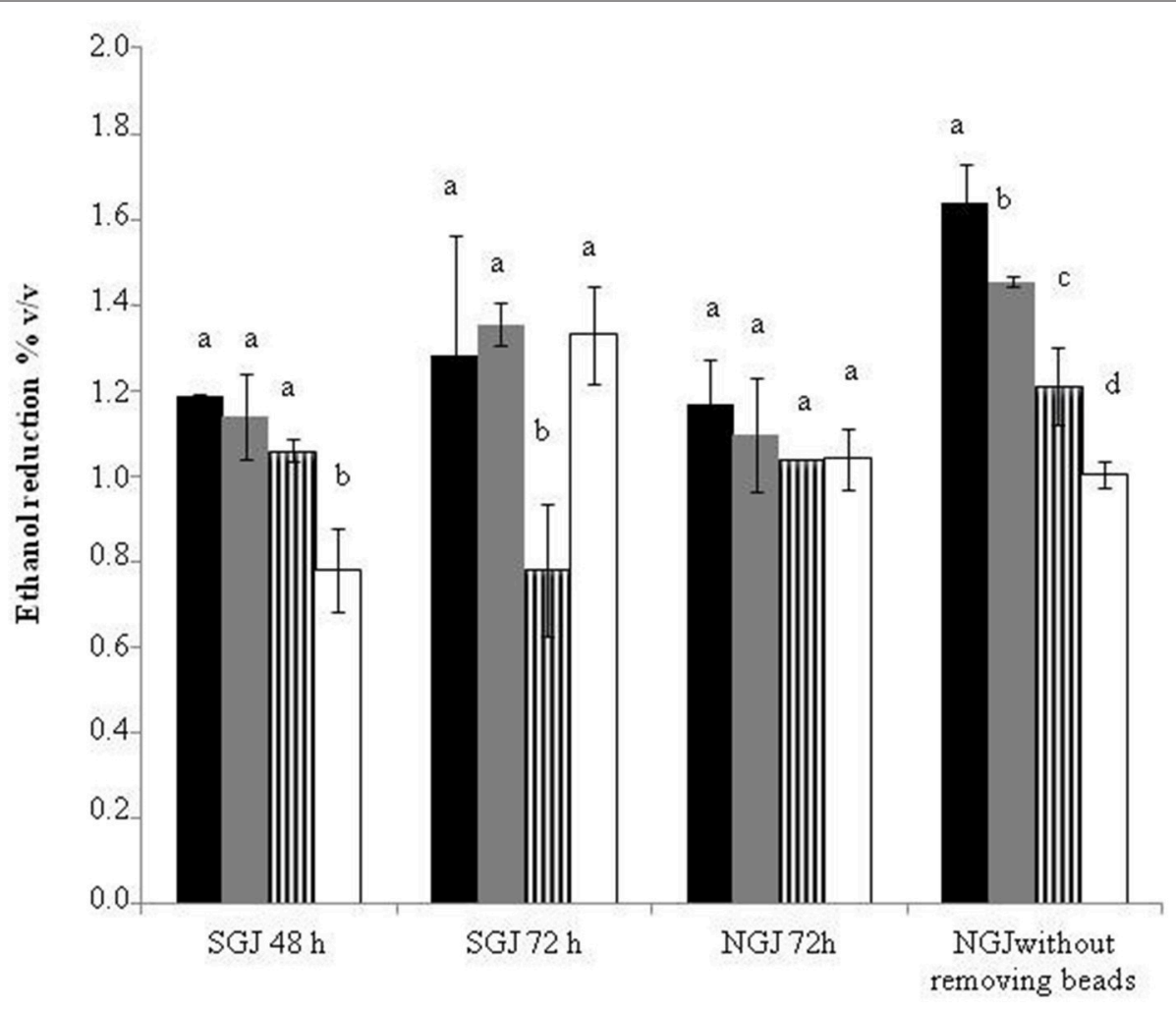

FIGURE 3 | Ethanol reduction with synthetic grape juice and natural grape juice. $\square$ S. bombicola/S. cerevisiae; $\square$ M. pulcherrima/S. cerevisiae; IIII H. uvarum/S. cerevisiae; $\square$ H. osmophila/S. cerevisiae. Data with different superscript letters (a,b,c,d) within each trials are different according to Duncan tests (0.05\%).

of fermentation of mixed fermentations results in significant reduction in ethanol production (Contreras et al., 2015b; Morales et al., 2015). Indeed, under limited aerated conditions, $M$. pulcherrima, Torulaspora delbrueckii, and Zygosaccharomyces bailii mixed fermentations resulted in reduced ethanol content, from 1.5 to $2.2 \%(\mathrm{v} / \mathrm{v})$, while under high agitation and aeration rates this resulted in unacceptable amounts of acetic acid by S. cerevisiae partner strain (Quirós et al., 2014; Contreras et al., 2015b). However, the effects of aerobic conditions on the analytical and sensorial profiles and oxygen modulation in mixed fermentations were not evaluated and for these reasons, the aeration of grape juice requires further investigations. Recently, under anaerobic conditions, a reduction in the alcohol level was achieved in fermentations performed using sequential inoculation with a strain of $M$. pulcherrima (Contreras et al., $2014,2015 a)$. Using a strain of $M$. pulcherrima in sequential fermentation trials, $50 \%$ of sugar consumed was achieved in white and red grape juice, with a delay of the second inoculation with $S$. cerevisiae strain of 9 and 17 days resulting in an ethanol reduction of 0.9 and $1.6 \%(\mathrm{v} / \mathrm{v})$, respectively (Contreras et al., 2014). However, a long delay for timing of second inoculation is difficult to manage under winery conditions, because of wild microflora contamination, where the competitiveness of the non-Saccharomyces strain is low, and the wild $S$. cerevisiae strains can easily dominate the fermentation process. 


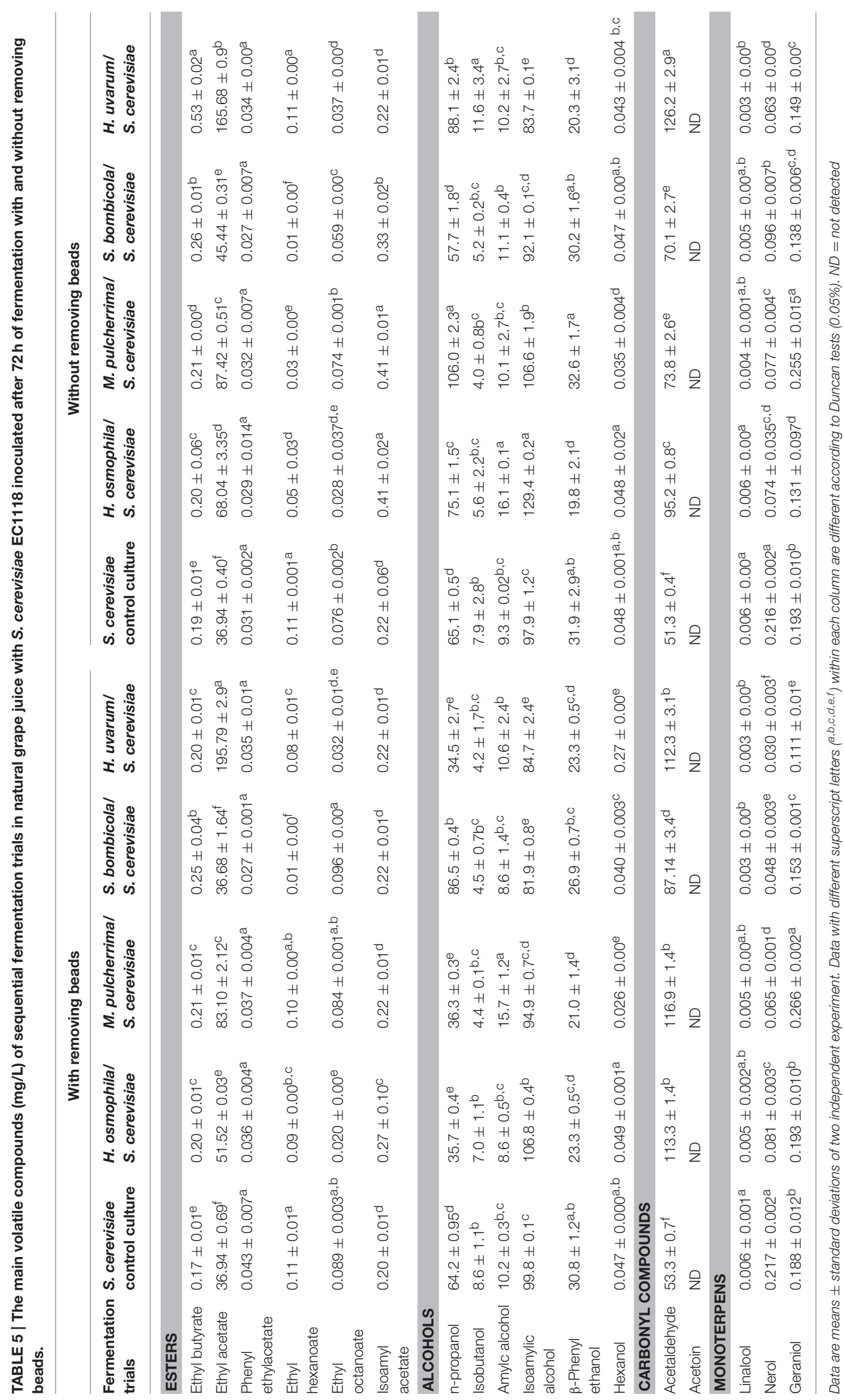


In this context, the management of non-Saccharomyces yeast in mixed fermentation trials with the aim to reduce the ethanol content is a crucial step. Indeed, to achieve sugar consumption of about 50\% using non-Saccharomyces yeast as the starter culture, a long delay of the $S$. cerevisiae starter inoculation would be needed. In the present study, we evaluated the use of four selected non-Saccharomyces strains in immobilized forms in both SGJ and NGJ, to obtain high inoculation levels and the consequent high metabolic activity, to reduce the time of the second inoculation. Under these conditions, with a delay of 3 days, we obtained a sugar consumption that ranged from 40 to $54 \%$ with an ethanol reduction from 1.0 to $1.17 \%(\mathrm{v} / \mathrm{v})$. Without removing beads, the alcohol reduction was further enhanced. Under these conditions, M. pulcherrima and S. bombicola confirmed the benefits for ethanol reduction in mixed fermentation trials than for those with $H$. uvarum and $H$. osmophila, which showed alcohol reductions of 1.4 and $1.6 \% \mathrm{v}(/ \mathrm{v})$, respectively. As previously shown, $M$. pulcherrima and $S$. bombicola in mixed fermentations, can reduce the ethanol content (Ciani and Ferraro, 1998; Contreras et al., 2014, 2015a,b; Quirós et al., 2014). The significant enhancement of by-products such as glycerol or succinic acid do not justify the ethanol reduction obtained. Other fermentation by-products that were not evaluated in this study and coming from glycerol-pyruvic fermentation or other metabolic pathways could explain this result. Moreover, pyruvate-metabolism is strictly linked to amino-acids, organic acids, and lipids biosynthesis and, consequently, sugar carbon could follow these pathways (Gancedo and Serrano, 1989).

Another important feature that should be highlighted is the analytical profile of final wines. In this context, the wine obtained showed in general comparable or better analytical profiles then for the control S. cerevisiae. Indeed, all fermentation trials showed

\section{REFERENCES}

Abalos, D., Vejarano, R., Morata, A., González, C., and Suárez-Lepe, J. A. (2011). The use of furfural as a metabolic inhibitor for reducing the alcohol content of model wines. Eur. Food Res. Technol. 232, 663-669. doi: 10.1007/s00217-0111433-9

Alstona, J. M., Fuller, K. B., James, T., Lapsley, J. T., and Soleas, G. (2011). Too much of a good thing? Causes and consequences of increases in sugar content of California wine grape. J. Wine Econom. 6, 135-159. doi: $10.1017 /$ S1931436100001565

AOAC (1990). Official Methods of Analyses, 15th Edn., Vol. 2. Washington, DC: Association of Official Analytical Chemists.

Athès, V., Lillo, M. P. Y., Bernard, C., Pérez-Correa, R., and Souchon, I. (2004). Comparison of experimental methods for measuring infinite dilution volatilities of aroma compounds in water/ethanol mixtures. J. Agric. Food Chem. 52, 2021-2027. doi: 10.1021/jf0350257

Belisario-Sánchez, Y. Y., Taboada-Rodríguez, A., Marín-Iniesta, F., and LópezGómez, A. (2009). Dealcoholized wines by spinning cone column distillation: phenolic compounds and antioxidant activity measured by the 1,1diphenyl-2-picrylhydrazyl method. J. Agric. Food Chem. 57, 6770-6778. doi: $10.1021 /$ jf900387g

Bindon, K., Varela, C., Kennedy, J., and Herderich, H. H. M. (2013). Relationships between harvest time and wine composition in Vitis vinifera L. cv. Cabernet Sauvignon 1. Grape and wine chemistry. Food Chem. 138, 1696-1705. doi: 10.1016/j.foodchem.2012.09.146 a limited increase of acetaldehyde content and only $H$. uvarum sequential fermentation exhibited significant amount of ethyl acetate that negatively affect the aroma profile of final wine. On the other hand, an enhancement in sequential fermentations of some desired compounds was shown. In particular, S. bombicola showed an enhancement in of glycerol and succinic acid, $M$. pulcherrima exhibited an increase in geraniol while $H$. osmophila displayed a significant increase in isoamyl acetate and isoamyl alcohol.

In conclusion, the non-Saccharomyces $M$. pulcherrima and $S$. bombicola are both promising wine yeast species for use in immobilized forms in sequential fermentation trials to reduce the ethanol content in wine. The use of high inoculation levels and immobilization procedures, however, results in substantial increases in the management costs of the fermentation process. For these reasons, further investigations are necessary to explore reductions in the bead concentrations, modulation of grape juice aeration, and evaluation of the sensorial profile of the resulting wine.

\section{FUNDING}

The work was financially supported by Ricerca Scientifica di Ateneo RSA2014 and RSA2015.

\section{AUTHOR CONTRIBUTIONS}

LC, LO, FC, and MC contributed equally to this manuscript. All authors participated in the design and discussion of the research. LC and LO carried out the experimental part of the work.LC, LO, MC, and FC carried out the analysis of the data and wrote the manuscript. All authors have read and approved the final manuscript.
Capozzi, V., Garofalo, C., Chiriatti, M. A., Grieco, F., and Spano, G. (2015). Microbial terroir and food innovation: The case of yeast biodiversity in wine. Microbiol Res. 181, 75-83. doi: 10.1016/j.micres.2015.10.005

Ciani, M., and Comitini, F. (2011). Non-Saccharomyces wine yeasts have a promising role in biotechnological approaches to winemaking. Ann. Microbiol. 61, 25-32. doi: 10.1007/s13213-010-0069-5

Ciani, M., and Ferraro, L. (1996). Enhanced glycerol content in wines made with immobilized Candida stellata cells. Appl. Environ. Microbiol. 62, 128-132.

Ciani, M., and Ferraro, L. (1998). Combined use of immobilized Candida stellata cells and Saccharomyces cerevisiae to improve the quality of wines. J. Appl. Bacteriol. 85, 247-254. doi: 10.1046/j.1365-2672.1998. 00485.x

Ciani, M., and Maccarelli, F. (1998). Oenological properties of non-Saccharomyces yeasts associated with winemaking. World J. Microbiol. Biol. 14, 199-203.

Comitini, F., Gobbi, M., Domizio, P., Romani, C., Lencioni, L., Mannazzu, I., et al. (2011). Selected non-Saccharomyces wine yeasts in controlled multistarter fermentations with Saccharomyces cerevisiae. Food Microbiol. 28, 873-888. doi: 10.1016/j.fm.2010.12.001

Contreras, A., Curtin, C., and Varela, C. (2015a). Yeast population dynamics reveal a potential 'collaboration' between Metschnikowia pulcherrima and Saccharomyces uvarum for the production of reduced alcohol wines during Shiraz fermentation. Appl. Microbiol. Biotechnol. 99, 1885-1895. doi: 10.1007/s00253-014-6193-6

Contreras, A., Hidalgo, C., Schmidt, S., Henschke, P. A., Curtin, C., and Varela, C. (2014). Evaluation of non-Saccharomyces yeasts for the reduction 
of alcohol content in wine. Appl. Environ. Microbiol. 80, 1670-1678. doi: 10.1128/AEM.03780-13

Contreras, A., Hidalgo, C., Schmidt, S., Henschke, P. A., Curtin, C., and Varela, C. (2015b). The application of non-Saccharomyces yeast in fermentations with limited aeration as a strategy for the production of wine with reduced alcohol content. Int. J. Food Microbiol. 205, 7-15. doi: 10.1016/j.ijfoodmicro.2015.03.027

Di Maio, S., Genna, G., Gandolfo, V., Amore, G., Ciaccio, M., and Oliva, D. (2012). Presence of Candida zemplinina in Sicilian musts and selection of a strain for wine mixed fermentations. S. Afr. J. Enol. Vitic. 33, 80-87.

Domizio, P., Romani, C., Comitini, F., Gobbi, M., Lencioni, L., Mannazzu, I., et al. (2011). Potential spoilage non-Saccharomyces yeasts in mixed cultures with Saccharomyces cerevisiae. Ann. Microbiol. 61, 137-144. doi: 10.1007/s13213010-0125-1

EC (2000). Commission Regulation (EC) no. 2870/2000 of 19 December 2000, Laying Down the Community Reference Methods for the Analysis of Spirits Drinks. Brussels: Official Journal of the European Communities.

Ehsani, M., Fernandez, M. R., Biosca, J. A., Julien, A., and Dequin, S. (2009). Engineering of 2,3-butanediol dehydrogenase to reduce acetoin formation by glycerol-overproducing, low-alcohol Saccharomyces cerevisiae. Appl. Environ. Microbiol. 75, 3196-3205. doi: 10.1128/AEM.02157-08

Ehsani, M., Renault, P., and Puente-López, V. (2012). L'impact organoleptique de Torulaspora delbrueckii en conditions oenologiques lors d'une inoculation séquentielle avec Saccharomyces cerevisiae. Rev. Oenologues. Tech. Vitivinicoles Oenologicques 39, 23-26.

Gancedo, C., and Serrano, R. (1989). "Energy yielding metabolism," in The Yeasts, Vol. 3, 2nd Edn., eds A. H. Rose and J. S. Harrison (London: Academic Press), 205-259.

Gawel, R., Van Sluyter, S., and Waters, E. J. (2007). The effects of ethanol and glycerol on the body and other sensory characteristics of Riesling wines. Aust. J. Grape Wine Res. 13, 38-45. doi: 10.1111/j.1755-0238.2007.tb00070.x

Gobbi, M., De Vero, L., Solieri, L., Comitini, F., Oro, L., Giudici, P., et al. (2014). Fermentative aptitude of non-Saccharomyces wine yeast for reduction in the ethanol content in wine. Eur. Food. Res. Technol. 239, 41-48. doi: 10.1007/s00217-014-2187-y

Gonzalez, R., Quiròs, M., and Morales, P. (2013). Yeast respiration of sugars by non-Saccharomyces yeast species: a promising and barely explored approach to lowering alcohol content of wines. Trend Food Sci. Technol. 29, 55-61. doi: 10.1016/j.tifs.2012.06.015

Grant, M. (2010). "Who is listening?", in Proceedings of the Fourteenth Australian Wine Industry Technical Conference; 3-8 July 2010; Adelaide, SA, Australia, eds R. Blair, T. H. Lee, and S. Pretorius (Urrbrae, SA: The Australian Wine Industry Technical Conference), 25-27.

Guth, H., and Sies, A. (2001). "Flavour of wines: towards an understanding by reconstitution experiments and an analysis of ethanol's effect on odour activity of key compounds," in Proceedings of the Eleventh Australian Wine Industry Technical Conference; 7-11 October 2001; Adelaide, SA, Australia, eds R. J. Blair, P. J. Williams, and P. B. Hoj (Urrbrae, SA: Australian Wine Industry Technical Conference), 128-139.

Jolly, N. P., Varela, C., and Pretorius, I. S. (2014). Not your ordinary yeast: nonSaccharomyces yeasts in wine production uncovered. FEMS Yeast Res. 14, 215-237. doi: 10.1111/1567-1364.12111

Jones, G. V., White, M. A., Cooper, O. R., and Storchmann, K. (2005). Climate change and global wine quality. Clim. Change 73, 319-343. doi: 10.1007/s10584005-4704-2

Kutyna, D. R., Varela, C., Henschke, P. A., Chambers, P. J., and Stanley, G. A. (2010). Microbiological approaches to lowering ethanol concentration in wine. Trends Food Sci. Technol. 21, 293-302. doi: 10.1016/j.tifs.2010.03.004
MacAvoy, M. G. (2010). "Wine - harmful or healthy? What is being considered in Australia and New Zealand?," in Proceedings of the Fourteenth Australian Wine Industry Technical Conference; 3-8 July 2010; Adelaide, SA, Australia, eds R. J. Blair, P. J. Williams, and S. Pretorius (Urrbrae, SA: Australian Wine Industry Technical Conference), 28-31.

Magyar, I., and Tóth, T. (2011). Comparative evaluation of some oenological properties in wine strains of Candida stellata, Candida zemplinina, Saccharomyces uvarum and Saccharomyces cerevisiae. Food Microbiol. 28, 94-100. doi: 10.1016/j.fm.2010.08.011

Morales, P., Rojas, V., Quirós, M., and Gonzalez, R. (2015). The impact of oxygen on the final alcohol content of wine fermented by a mixed starter culture. Appl. Microbiol. Biotechnol. 99, 3993-4003. doi: 10.1007/s00253-014-6321-3

Morata, A., Benito, S., Loira, I., Palomero, F., González, M. C., and Suarez-Lepe, J. A. (2012). Formation of pyranoanthocyanins by Schizosaccharomyces pombe during the fermentation of red must. Int. J. Food Microbiol. 159, 47-53. doi: 10.1016/j.ijfoodmicro.2012.08.007

Quirós, M., Rojas, V., Gonzalez, R., and Morales, P. (2014). Selection of non-Saccharomyces yeast strains for reducing alcohol levels in wine by sugar respiration. Int. J. Food Microbiol. 181, 85-91. doi: 10.1016/j.ijfoodmicro.2014.04.024

Renouf, V., Claisse, O., and Lonvaud-Funel, A. (2005). Understanding the microbial ecosystem on the grape berry surface through numeration and identification of yeast and bacteria. Aust. J. Grape Wine Res. 11, 316-327. doi: 10.1111/j.1755-0238.2005.tb00031.x

Renouf, V., Strehaiano, P., and Lonvaud-Funel, A. (2007). Yeast and bacteria analysis of grape, wine and cellar equipment by PCR-DGGE. Int. J. Sci. Vin. Vigne 41, 51-61.

Rossouw, D., Heyns, E. H., Setati, M. E., Bosch, S., and Bauer, F. F. (2013). Adjustment of trehalose metabolism in wine Saccharomyces cerevisiae strains to modify ethanol yields. Appl. Environ. Microbiol. 79, 5197-5207. doi: 10.1128/AEM.00964-13

Schmidtke, L. M., Blackman, J. W., and Agboola, S. O. (2012). Production technologies for reduced alcoholic wines. J. Food Sci. 77, R25-R41. doi: 10.1111/j.1750-3841.2011.02448.x

Stoll, M., Lafontaine, M., and Schultz, H. R. (2010). Possibilities to reduce the velocity of berry maturation through various leaf area to fruit ratio modifications in Vitis vinifera L. Riesling. Progrès Agricole et Viticole. 127, 68-71.

Tilloy, V., Ortiz-Julien, A., and Dequin, S. (2014). Biotechnology reduction of ethanol yield and improvement of glycerol formation by adaptive evolution of the wine yeast Saccharomyces cerevisiae under hyperosmotic conditions. Appl. Environ. Microbiol. 80, 2623-2632. doi: 10.1128/AEM. 03710-13

Varela, C., Kutyna, D. R., Solomon, M. R., Black, C. A., Borneman, A., Henschke, P. A., et al. (2012). Evaluation of gene modification strategies for the development of low-alcohol-wine yeasts. Appl. Environ. Microbiol. 78, 6068-6077. doi: 10.1128/AEM.01279-12

Conflict of Interest Statement: The authors declare that the research was conducted in the absence of any commercial or financial relationships that could be construed as a potential conflict of interest.

Copyright () 2016 Canonico, Comitini, Oro and Ciani. This is an open-access article distributed under the terms of the Creative Commons Attribution License (CC BY). The use, distribution or reproduction in other forums is permitted, provided the original author(s) or licensor are credited and that the original publication in this journal is cited, in accordance with accepted academic practice. No use, distribution or reproduction is permitted which does not comply with these terms. 